\title{
Hardness behavior of W. Nr. 1.7709 steel, oil quenched and tempered between $475^{\circ} \mathrm{C}$ and $575^{\circ} \mathrm{C}$
}

\author{
John Mantzoukas ${ }^{1}$, Dimitris G. Papageorgiou ${ }^{1}$, Carmen Medrea $^{1 *}$ and Constantinos Stergiou ${ }^{1}$ \\ ${ }^{1}$ Department of Mechanical Engineering, University of West Attica, 250 Thivon \& Petrou \\ Ralli Ave. 12244 Egaleo, Greece
}

\begin{abstract}
Steel components frequently involve a heat treatment to improve mechanical properties. In order to meet difficult working conditions, several components are hardened by quenching. W. Nr. 1.7709 is a representative structural steel with very low thermal conductivity among EN wrought alloy steels, which is extensively used after hardening and tempering. Although the steelmakers provide technical information about their heat treatment sequence, the tempering diagram of the specific grade has not been designed yet. The present paper analyses the temper resistance of the specific steel after oil quenching and tempering at high temperatures. Samples of identical chemical compositions were accordingly prepared and randomized. Five groups of ten specimens were austenitized at $960^{\circ} \mathrm{C}$, hold for 30 minutes and were quenched in oil. They were tempered for two hours at different temperatures between $475^{\circ} \mathrm{C}$ and $575^{\circ} \mathrm{C}$. Specific temperatures are interesting to the heat treaters, as they could allow certain transformations which take place during tempering. Hardness measurements were carried out and statistically processed. The tempering diagram was plotted to the specified temperature range. The influence of tempering temperature on steel hardness was analysed and the resistance to tempering back of the steel was discussed. The tempering diagram is critical for metallurgists as it represents a guide to define the proper tempering parameters so that the hardness predicted according to the mechanical property requirements are obtained.
\end{abstract}

\section{Introduction}

Steel components frequently involve heat treatment in order their mechanical properties to be improved. Over time various hardening techniques have been developed for this purpose [1]. Nowadays, metallurgists work to expand the outcome and increase cost-efficiency of these processes. Hardening by quenching is the most common of all techniques, widely applied in steel upgrading [2]. The working pieces are heated above the upper critical temperature, they are kept there to assure austenitizing and are cooled with a rate that ensures the martensitic transformation [1]. The quenching induces high stresses on the material and leads to a considerably harder and extremely brittle component. Therefore, tempering is performed immediately after quenching (Fig.1). The parts are reheated below the lower 
critical temperature, where they are held for a specific time before they are left on air to reach room temperature [3].

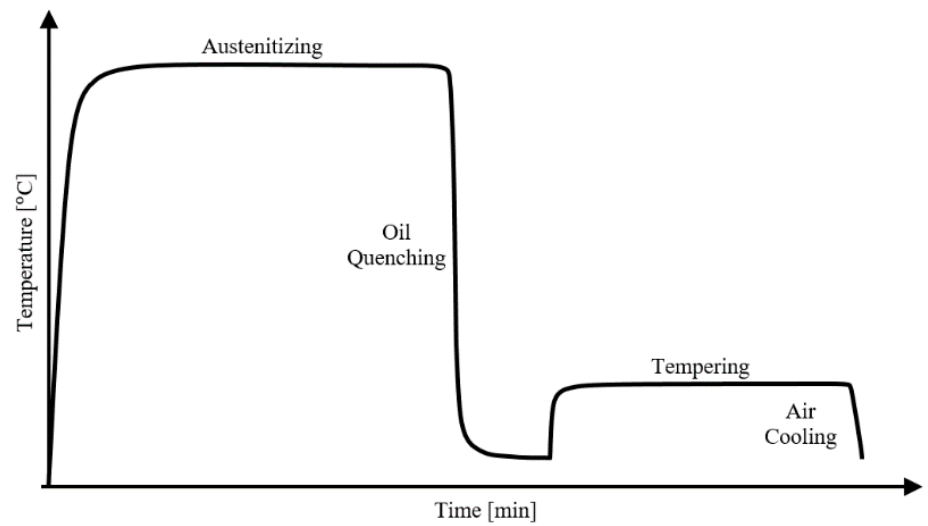

Fig. 1. Time-temperature diagram showing hardening by quenching and tempering.

The changes in microstructure and substructure produced by tempering relieve the internal stress and concomitantly, eliminate the brittleness of fully hardened steels (by decreasing the hardness to a specified range) and improve strength and toughness [4]. The process parameters (temperature and time) define the final properties of the steel [5]. In most applications, the holding time ranges from one to two hours. Therefore, tempering temperature generally determines the proper combination of hardness, strength and toughness of any part according to engineering requirements $[6,7]$. The steel manufacturers provide technical information regarding the quenching conditions of the most common grades. A very useful tool is the tempering diagram. It represents the hardness behaviour as a function of tempering temperature for suitable holding time (Fig. 2). This information represents a guide for individual pieces.

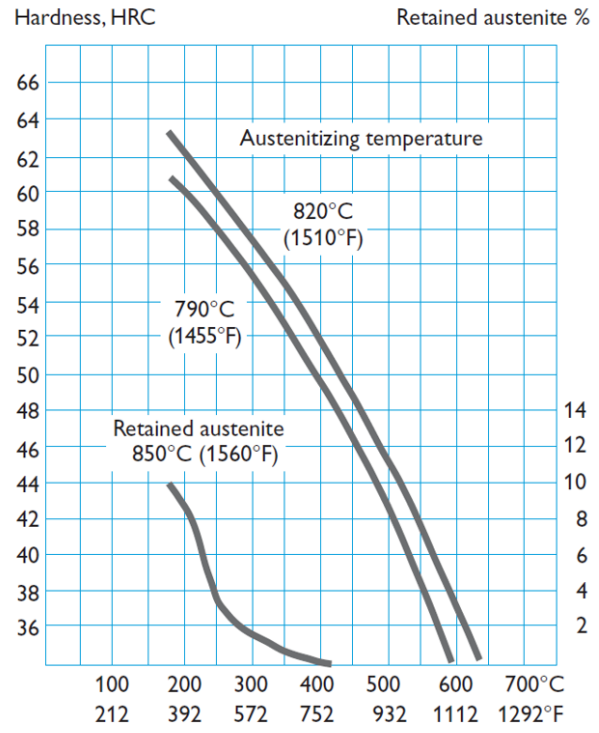

(a)

Tempering temperature

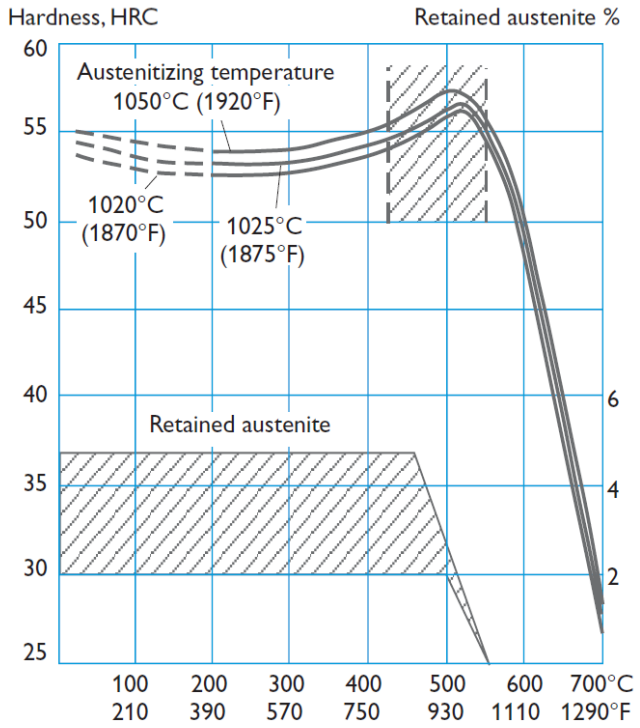

(b)

Tempering temperature $(2 h+2 h)$

Fig. 2. Example of tempering diagram; (a) AISI O1 [8], (b) AISI H13[9] 
Mechanical components hardened by quenching can be found in all industrial sectors from power production industry, mining, chemical industry, metallurgy to all means of transport, defence industry, agriculture and generally anywhere a tool or a machine is needed $[10,11]$. Thus, these parts are manufactured in a huge range of geometry and dimensions (eg. spindles, gears, shafts, cams, various cutting tools, different moulds, etc.). All pieces are of increased hardness and wear resistance. Additionally, the machine components of alloyed steels acquire improved yield strength, toughness and ductility [12].

In order to cover rising demands in structures, metallurgists develop new steelmaking processes to produce a variety of grades. Everyone refers to alloying, rate of heating, holding and cooling the metal. A particular group of steel, the structural steels have been designed for critical applications. They have been alloyed with elements enough to rend the parts hardened, to become corrosion resistant, heat resistant, wear resistant and to add singular physical and chemical properties as well [13]. W. Nr 1.7709 (or DIN 21CrMoV5-7) is one of the most representative steel grades [14]. Through quenching, its alloying elements (chromium, molybdenum and vanadium) provide improved yield and tensile strength, adequate plasticity and toughness as well as excellent corrosion, heat and high wear resistance [15]. The steel is extensively used in the construction of ships, vehicles, airplanes, railways, bridges, and machine tools [16]. It has also become a common choice in manufacturing of components of various shapes and dimensions which work at high temperature, such as turbine fasteners, mechanical gears, rods, complex shafts, pressure vessels, seamless pipes, etc. $[11,13]$. Although the steel manufacturers provide technical information on its chemical composition, its range of application, its processing condition, its heat treatment and properties under various conditions, the tempering diagram is absent.

The specific work is part of a large project aimed to plot the tempering diagram of 1.7709 steel. It particularly depicts the hardness variation of the steel after oil quenching and tempering between $475^{\circ} \mathrm{C}$ and $575^{\circ} \mathrm{C}$. The specific temperature range is interesting to the heat treaters as they could allow certain transformations which take place during tempering, as secondary hardening [17]. The tempering diagram constitutes a valuable asset for the steel industry, as it assists heat treaters to define the proper tempering parameters, so they obtain the predicted hardness according to the predicted property requirements.

\section{Experimental Details}

The present research is a part of a large project aimed to plot the tempering diagram of the steel. The experimental part followed the same procedure which was initially developed during tempering the steel at low temperatures [18]. All necessary material for the experiment was initially acquired, from the same manufacturer. Supplying steel from the same batch was mandatory in order to assure identical chemical composition to all samples. The bars in the delivered condition were $25.4 \mathrm{~mm}$ in diameter and were $4 \mathrm{~m}$ long. They were cut in rods $1 \mathrm{~m}$ long (Fig. $3 \mathrm{a}$ ). The rods were machined in a conventional lathe to $23 \mathrm{~mm}$ diameter, in order to remove possible chemical and microstructural non-uniformities, due to steelmaking process steps. Then, they were further cut in specimens $25 \mathrm{~mm}$ in length (Fig.3b). All specimens were marked (Fig.3c), and randomized (using Minitab 17) in order to assure high rate of homogeneity in hardness results considering material irregularities.

A set of fifty (50) randomized specimens was divided into five groups of 10 pieces (Group I to Group V). All groups were hardened to the same condition and tempered at different temperatures. Nominal hardening conditions were selected according to the steelmaker's specifications. The hardening was realized by austenitizing at $960^{\circ} \mathrm{C}$, holding for 30 minutes and oil quenched at room temperature (Fig 4). Rockwell hardness was measured after quenching on two random selected pieces of each group, in order to verify that all parameters 
of the experiment, except tempering temperature were held constant (Table 1). Six hardness measurements (HV 30) were carried out on the cross section of the sample (Fig. 5).
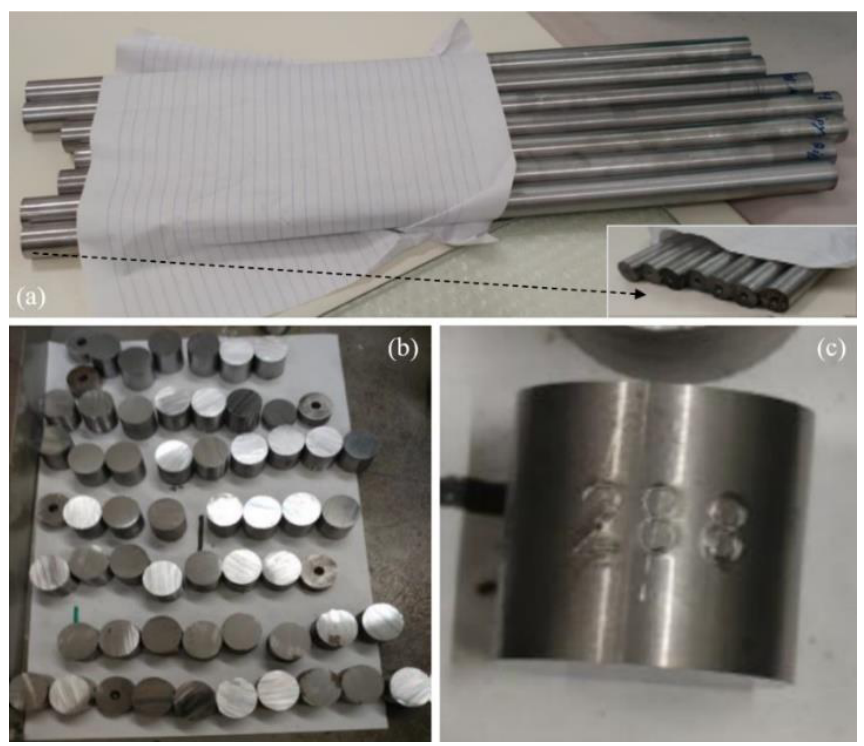

Fig. 3. Photographs showing sample preparation: (a) Bars cutting and hole drilling detail, (b) Sample cutting, (c) Samples marked in order to be randomized.
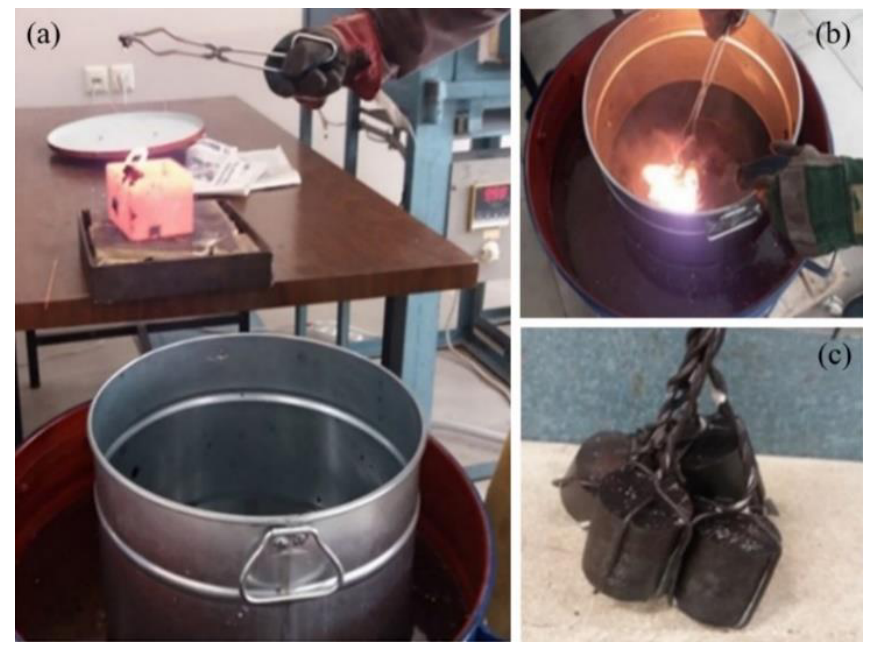

Fig. 4. Images showing the oil quenching of samples.

Table 1. Heat treatment sequence

\begin{tabular}{|c|c|c|c|c|c|}
\hline \multirow[b]{2}{*}{ Samples } & \multicolumn{2}{|c|}{ Austenitizing } & \multirow{2}{*}{$\begin{array}{c}\text { Quenching } \\
\text { media }\end{array}$} & \multicolumn{2}{|c|}{ Tempering } \\
\hline & $\begin{array}{c}\text { Temperature } \\
\mathbf{T}_{\mathrm{a}}\left[{ }^{\circ} \mathbf{C}\right]\end{array}$ & $\begin{array}{c}\text { Time } \\
t_{a}[\text { min }]\end{array}$ & & $\begin{array}{c}\text { Temperature } \\
\mathbf{T}\left[{ }^{\circ} \mathbf{C}\right]\end{array}$ & $\begin{array}{c}\text { Time } \\
T \text { [min] }\end{array}$ \\
\hline Group I & \multirow{5}{*}{960} & \multirow{5}{*}{30} & \multirow{5}{*}{ oil } & 475 & \multirow{5}{*}{120} \\
\hline Group II & & & & 500 & \\
\hline Group III & & & & 525 & \\
\hline Group IV & & & & 550 & \\
\hline Group V & & & & 575 & \\
\hline
\end{tabular}




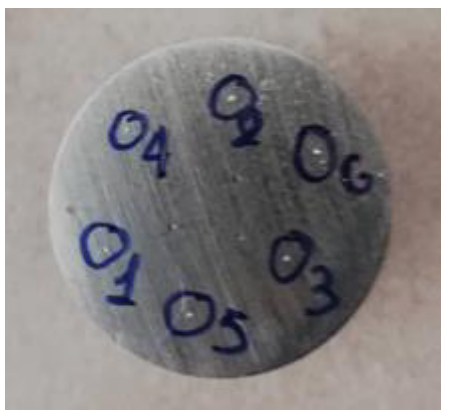

Fig. 5. Schematics of the hardness measurement points on the sample cross section.

Vickers was selected for the measurements as more accurate method. The results were statistically processed, according to engineering practice (95\% reliability), and using Minitab 17 [1]. Hardness range was converted to Rockwell C, as it is used in designing tempering diagrams and is more popular in practice [19]. The tempering diagram was plotted for the specific range of temperatures.

\section{Results and Discussion}

The final hardness of every specimen is depended on diverse factors as the chemical composition, non-uniformity of material induced by previous processing steps, different quenching conditions, or human factors. The feature is very important for the success of the experiment and to ensure that the hardness depends only on tempering temperature, all other factors must be kept constant. The chemical composition of the steel was verified by randomly selected samples and was compared to the standard specification [20]. The results show that the chemical composition of the material was conforming to the standard (Table 2). Furthermore, all specimens have almost identical chemical composition.

Table 2. Chemical composition of 1.7709 steel.

\begin{tabular}{|c|c|c|c|c|c|c|c|c|c|c|}
\hline $\begin{array}{c}\text { Chemical } \\
\text { Elements [\%] }\end{array}$ & $\mathbf{C}$ & $\mathbf{S i}$ & $\mathbf{M n}$ & $\mathbf{N i}$ & $\mathbf{P}$ & $\mathbf{S}$ & $\mathbf{C r}$ & $\mathbf{M o}$ & $\mathbf{V}$ & $\mathbf{A l}$ \\
\hline $\begin{array}{c}\text { Steel as } \\
\text { delivered }\end{array}$ & 0.23 & 0.32 & 0.70 & 0.45 & 0.013 & 0.002 & 1.45 & 0.71 & 0.285 & 0.02 \\
\hline $\begin{array}{c}\text { Nominal } \\
\text { composition } \\
\text { BS EN 10269 }\end{array}$ & $\begin{array}{c}0.17 \\
-\end{array}$ & $\begin{array}{c}\max \\
0.4\end{array}$ & $\begin{array}{c}0.4 \\
-\end{array}$ & $\begin{array}{c}\max \\
0.6\end{array}$ & $\begin{array}{c}\max . \\
0.03\end{array}$ & $\begin{array}{c}\max \\
0.03\end{array}$ & $\begin{array}{c}1.2 \\
-\end{array}$ & $\begin{array}{c}0.55 \\
-\end{array}$ & $\begin{array}{c}0.2 \\
-\end{array}$ & $\max$ \\
0.03 \\
\hline
\end{tabular}

Five groups of ten specimens were hardened under the same conditions: austenitizing at $960^{\circ} \mathrm{C}$ for 30 minutes and oil quenching at room temperature (Table 1). Any difference, up to technical recommendations could affect the reliability of the experiment results. For the scope of the present work, the resulting of the quenching process in uniform hardness was mandatory. It was verified by the measurement of two randomly selected specimens of each group. In the technical data sheet of the material, a maximum variation of $4 \mathrm{HRC}$ is referred. All hardness values lie between 40HRC (392 HV) and 44HRC (434 HV). The fact that all specimens were hardened to $42+2 \mathrm{HRC}$ proves that hardening was successfully performed, and the repeatability of the process was secured [21].

All hardened groups were tempered for two hours at $475^{\circ}, 500^{\circ}, 525^{\circ}, 550^{\circ}$, and $575^{\circ} \mathrm{C}$ respectively and were cooled in air at room temperature. Vickers hardness measurements were performed on the cross section of each specimen and the mean value was used for statistical analysis with Minilab 17 (Table 3). 
Six hardness measurements were performed on the cross section of each specimen and the mean value of each sample was used for statistical analysis. On Table 3, the mean hardness value (Mean value), the standard deviation (S.D.), the 95\% Confidence Interval (C.I. 95\%) and the hardness range on Vickers and on Rockwell scale of each group are shown. The hardness behaviour of the steel was then plotted as function of tempering temperature (Fig. 6).

Table 3.W. Nr 1.7709 hardness variation in function of tempering temperature

\begin{tabular}{|c|c|c|c|c|c|c|c|c|c|}
\hline \multicolumn{10}{|c|}{ Tempering Temperature $\left[{ }^{\circ} \mathrm{C}\right]$} \\
\hline \multicolumn{2}{|c|}{475 (Group I) } & \multicolumn{2}{|c|}{500 (Group II) } & \multicolumn{2}{|c|}{525 (Group III) } & \multicolumn{2}{|c|}{550 (Group IV) } & \multicolumn{2}{|c|}{575 (Group V) } \\
\hline Sample & $\overline{\mathrm{HV} 30}$ & Sample & $\overline{\mathrm{HV} 30}$ & Sample & $\overline{\mathrm{HV} 30}$ & Sample & $\overline{\text { HV30 }}$ & Sample & $\overline{\mathrm{HV} 30}$ \\
\hline 1 & 370 & 11 & 387 & 21 & 380 & 31 & 402 & 41 & 370 \\
\hline 2 & 375 & 12 & 449 & 22 & 385 & 32 & 370 & 42 & 378 \\
\hline 3 & 375 & 13 & 398 & 23 & 378 & 33 & 413 & 43 & 385 \\
\hline 4 & 415 & 14 & 420 & 24 & 374 & 34 & 398 & 44 & 382 \\
\hline 5 & 382 & 15 & 398 & 25 & 384 & 35 & 415 & 45 & 374 \\
\hline 6 & 385 & 16 & 427 & 26 & 385 & 36 & 395 & 46 & 380 \\
\hline 7 & 380 & 17 & 425 & 27 & 382 & 37 & 427 & 47 & 384 \\
\hline 8 & 376 & 18 & 403 & 28 & 400 & 38 & 396 & 48 & 378 \\
\hline 9 & 371 & 19 & 393 & 29 & 379 & 39 & 409 & 49 & 382 \\
\hline 10 & 384 & 20 & 390 & 30 & 369 & 40 & 399 & 50 & 381 \\
\hline Mean Value & 381 & Mean Value & 409 & Mean Value & 382 & Mean Value & 402 & Mean Value & 379 \\
\hline S.D. & 12,9 & S.D. & 20,2 & S.D. & 8,2 & S.D. & 15,3 & S.D. & 4,6 \\
\hline C.I. $95 \%$ & 9,2 & C.I. 95\% & 14,5 & C.I. $95 \%$ & 5,9 & C.I. $95 \%$ & 10,9 & C.I. $95 \%$ & 3,3 \\
\hline HV30 & $381 \pm 9,2$ & HV30 & $409 \pm 14,5$ & HV30 & $382 \pm 5,9$ & HV30 & $402 \pm 10,9$ & HV30 & $379 \pm 3,3$ \\
\hline HRC & $38,9 \pm 0,9$ & HRC & $41,7 \pm 1,4$ & HRC & $39 \pm 0,6$ & HRC & $41 \pm 1,1$ & HRC & $38,7 \pm 0,3$ \\
\hline
\end{tabular}

\section{5\% C.I. for the Mean}

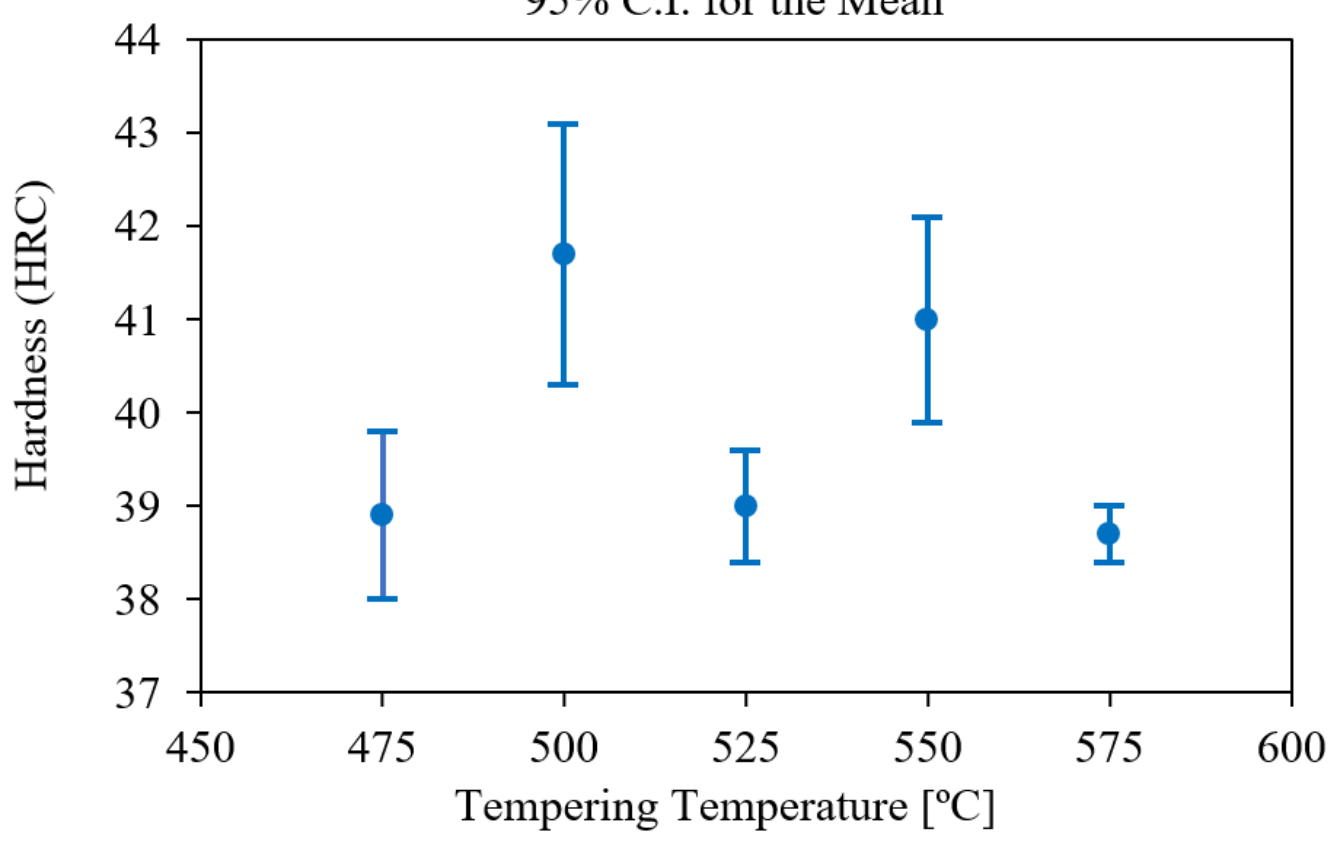

Individual standard deviations were used to calculate the intervals

Fig. 6. Tempering diagram of 1.7709 steel at temperatures between 475 and $575^{\circ} \mathrm{C}$. 
The tempering resistance of low alloy steels is limited featuring a descending mode in hardness as the tempering temperature is increasing. Tempering of the steel between $475^{\circ} \mathrm{C}$ and $575^{\circ} \mathrm{C}$ resulted to a hardness range between $381 \mathrm{HV}$ (39HRC) and 409HV (42HRC). In this case, the acquired hardness is showing slight fluctuations indicating that the specific steel grade is resisting to tempering back. Due to precipitation of chromium, molybdenum and vanadium carbides (as shown in Figure 6), the calculated S.D. is higher in $500^{\circ} \mathrm{C}$ and $550^{\circ} \mathrm{C}$ respectively. In the same way, the maximum standard deviation of $20.2 \mathrm{HV}$, was found in the case of tempering at $500^{\circ} \mathrm{C}$; resulting to the maximum confidence interval.

\section{Conclusion}

Tempering temperature strongly influences steel hardness during its heat treatment. By tempering 1.7709 steel from $475^{\circ} \mathrm{C}$ to $575^{\circ} \mathrm{C}$ its hardness is in general kept constant while having minor fluctuations. Nevertheless, there are two hardness picks in $500^{\circ} \mathrm{C}$ and $550^{\circ} \mathrm{C}$. The specific temperature range is where the secondary hardening (by carbide precipitation) in alloy steels occurs increasing the steel hardness further near to the values after quenching. A microscopic investigation is in progress. In order to validate the conclusions, the experiment should be extended to higher tempering temperatures.

\section{Acknowledgment}

The authors gratefully acknowledge A. Dragatsis, S. Moutzouri and J. Rachoutis, undergraduate students at University of West Attica for their contribution to the experimental processes.

\section{References}

1. H. Chadler, Heat Treater's Guide-Practices and Procedures of Iron and Steel, 2, ASM International, Materials Park, Ohio,16-26 (1995).

2. S. Jahanti, Technical Fact, Hardening of Steel: Objectives and Components Metallurgy, (2021), Available at: https://www.engineeringenotes.com/metallurgy/ steel/hardeningof-steel-objectives-and-components-metallurgy/26162 (Accessed 15-07-21).

3. G.R. Speich, W.C. Leslie, Tempering of steel, Metallurgical Material Transactions, 3, 1043-1054 (1972).

4. G. Krauss, Tempering of martensite in carbon steels, Phase Transformations in Steels, 2, 126-150 (2012).

5. R.A. Grange, C.R. Hribal, L.F. Porter, Hardness of tempered martensite in carbon and low-alloy steels. Metall Mater Trans A 8, 1775-1785 (1977).

6. A. Anazadeh Sayed, Sh. Kheirandish, Affect of the tempering temperature on the microstructure and mechanical properties of dual phase steels, Materials Science and Engineering : A, 532, 21-25 (2012).

7. G. Krauss, Tempering of Lath Martensite in Low and Medium Carbon Steels: Assessment and Challenges, Steel Research International (2017).

8. Uddeholm, Technical fact, Arne (2014), Available at: https://www.uddeholm.com/files/PB_Uddeholm_arne_english.pdf (Accessed 25/08/2021). 
9. Uddeholm Technical Fact, Orvar Supreme, (2013) Available at: https://www.uddeholm.com/files/PB_orvar_supreme_english.pdf (Accessed 2/07/2021).

10. W. Bryson, Heat Treatment, Selection, and Application of Tool Steels. München: Hanser, Carl (2013).

11. Virgramet, 21CrMoV5-7, 1.7709, 21CrMoV5-11, 1.8070, Available at: https://virgamet .com/21 crmov57-1-7709-21 crmov511-1-8070-20cdv507-21hmf-boiler-steel (Accessed 11-07-21).

12. Metlab Com., Metal hardening/ Metal Quenching/ Metal tempering, Available at: https://www.metlabheattreat.com/metal-hardening-metal-quenching-metaltempering.html (Accessed 17-07-2021),

13. Loghai Steel Com, Technical fact, 21CrMoV5-7 / 1.7709, (2011), Available at: http://www.ccsteels.com/Structural_steel/2570.html (Assessed 07/07/2021).

14. Steel fact, European Steel and Alloy Grades/Numbers Steel Number. 21CrMoV5-7 (1.7709), (2021) Available at: http://www.steelnumber.com/en/steel_composition eu.php?name id=674 (Accessed 12-07-2021),

15. Makeitfrom, EN 1.7709 (21CrMoV5-7), (2018), Steel, Available at : https://www.makeitfrom.com/material-properties/EN-1.7709-21CrMoV5-7-Steel (Accessed 07/07/2021),

16. Otaisteel, DIN 21CrMoV5-7 / W-Nr. 1.7709 Steel, (2017), Available at: http://www.otaisteel.com/21crmov57-tool-steel/ (Accessed 11-07-21),

17. M. Gojic, L. Kosec, P. Matkovic, The effect of tempering temperature on mechanical properties and microstructure of low alloy $\mathrm{Cr}$ and CrMo steel. Journal of Materials Science, 33, 395-403, (1998).

18. S. Katsimardos, Tempering resistance of 1.7709 steel at low temperatures. MSc thesis, TEI Piraeus - Kingston University, (2017).

19. ASTM International, ASTM E140 - Standard Hardness Conversion Tables for Metals Relationship among Brinell Hardness, Vickers Hardness, Rockwell Hardness, Superficial Hardness, Knoop Hardness, and Scleroscope Hardness, ASTM International, West Conshohocken, PA (2007).

20. BS EN 10269, Steels and nickel alloys for fasteners with specified elevated and/or low temperature properties, (2013).

21. C. Ktenas, D.G. Papageorgiou, C. Medrea, C. Stergiou, (2018). The influence of tempering temperature on steel hardness after quenching and tempering at temperatures between $275^{\circ} \mathrm{C}$ and $375^{\circ} \mathrm{C}, 13^{\text {th }}$ International Scientific Conference, eRa13, Athens, Greece, 21-23 November (2020). 